\title{
The Effect of Moisture on the Strength of Concrete Sample by using Ultrasonic Device
}

\section{Abolfazl Hassani', Bahram Shokouhi Mashhadi $^{2 *}$, Abouzar Shafipour ${ }^{2}$, Mohammad Bazrafkan'}

'School of Civil \& Environmental Engineering, Tarbiat Modares University

${ }^{2}$ Civil Engineering (Transportation), North Tehran Branch, Payame Noor University, Tehran, Iran

Study Area: Tehran, Iran

Coordinates: $35^{\circ} 41^{\prime} 46^{\prime \prime} \mathrm{N} ; 51^{\circ} 25^{\prime} 23^{\prime \prime} \mathrm{E}$

Key words: Micro silica, Forta fibers, Concrete strength,

\section{Abstract}

Testing through the ultrasonic waves is one of the most important non-destructive methods for evaluating the compressive strength of the concrete. The result of this test is based on the velocity of ultrasonic waves through the concrete.This study examines the effect of moisture on the velocity of ultrasonic waves and compressive strength of concrete. The ultrasound equipment used in this study shows that non-destructive ultrasonic waves generated by portable devices Pundit with a range of $500 \mathrm{~V}$ and waves 54 $\mathrm{KHz}$. The required time for signal transmission among the transducers was calculated as a parameter for evaluating the signal speed.The results of the analysis show that moisture has the signif icant effect on the velocity of ultrasonic waves and compressive strength of concrete. By placing the concrete samples in water and raising the content of moisture, the speed of ultrasonic waves is enhanced but the compressive strength of samples is reduced. With high moisture content, the velocity of ultrasonic waves and compressive strength are found to be inversely related.

\section{Introduction:}

Nowadays, the concrete assessment of quality control is carried out by using non-destructive methods. On the other hand beside the resulted oriented it reduced costs and time of test and ease for employing as compared to the other destructive and non-destructive methods. This phenomenon is considered by engineers all over the world by different techniques (Bungey et al., 2006). One of the first non-destructive methods used to assess concrete was the velocity of ultrasonic waves technique. The literature review shows that ultrasonic waves mainly be used to predict concrete strength. However, this method can also be used to detect internal defects of concrete such as cracks, delamination (Lin et al., 2003).

The mechanical waves of ultrasonic waves of have a frequency of more than $20 \mathrm{kHz}$. The behaviour of these waves is essentially the same as audible sound waves. Since ultrasonic waves do not transmit through the air or vacuum, therefore, the Couplant material such as ultrasound gel to fill the empty spaces between the converters and the concrete surface waves is used to transmit or receive (Abo-Qudais, 2005).The distribution of ultrasonic waves in concrete depends on its uneven

structure. The transition between the aggregates and hydraulic cement paste tends to reflect one part of the ultrasonic waves from the main beams (Abo-Qudais, 2005). The attenuation and propagation of ultrasonic waves in concrete were studied by using frequencies in the range of $25-250 \mathrm{KHz}$. Evaluation of the compressive strength of concrete by using ultrasonic methods according to the nature of the test is subject to a number of factors. The most important one among them is the ratio of water to cement, aggregates, concrete age, and types condition of preserving, and moisture content. These parameters must be considered by the researchers (Facaoaru, 1970).

Gaydecki et al. (1992) examined the propagation and attenuation of waves in concrete at different frequencies. Malhotra (1976) studied the velocity of waves in concrete samples with different ratios of water and types of different aggregates.Factory with multiple tests on made concrete samples with a variety of aggregates usually offered the ranges of waves' speed depending on the type of aggregate (Facaoaru, 1970). Demirboga et al. (2004) also examined the relationship between the velocity of ultrasonic waves and the strength of concrete with mineral additives. 


\section{Materialsand Method:}

Laboratory setting: evaluation of the compressive strength of concrete using ultrasonic methods depends on the nature of the test which is subject to a number of factors. The most important one among them is the ratio of water to cement, aggregates, concrete age, condition of preserving, and moisture content. This study considered the effect of humidity on the characteristics of normal concrete, containing fibre and micro silica. In order to achieve the aim of the study, the concrete samples were kept in 6 groups with a different ratio of water to cement and made aggregate in the same condition. On the 28 th day, it set with different moisture contents when they were tested by ultrasonic testing and compressive strength.

Sample Preparation: In preparing the samples, the cement type II was used. The stone materials were broken river types and their physical properties are shown in "Table-1". The water that used in the manufacture and curing of concrete was from drinking water used in Tehran, Iran. As well as the used fibre was Forta polymer fibre. Forta Ferro is a fibre composed of different combinations, made of $100 \%$ net copolymer or polypropylene that consist of very thin convoluted string together and form a knot and a string fibre network. It creates a system of reinforced concrete with very high efficiency and quality. In this study, the amount of fibre used was 2.0 and $4.0 \%$ by volume for testing. It is worth in order to calculate the amounts of these fibres in the mix design; the special weight for them is 0.91g. $\mathrm{cm}^{3}$ (Table-2). In the current investigation, Micro silica was one of the best mineral additives, in other words, it was a super pozzolan that has a significant impact on increased strength and durability of concrete structures. It was used in the construction of concrete samples. In this study, the amount of micro silica was $7 \%$ of cement weight for testing.

In this study, we used normal, fibre and micro silica concrete with a ratio of water to cement $\mathrm{W} / \mathrm{C}=0.61$, which their mixed design was provided in "Table-3".

Testing sample: the samples on the 28th day were examined having different content of moisture under the test of ultrasonic and compressive strength in compliance with the standard requirements B compressive strength $\mathrm{S}$ 1881 (Trtnik \& Gams, 2014).

Ultrasonic equipment used in this research includes Pulsar, Pundit receiver. Machines for making and receiving ultrasonic waves have a digital monitor to show the results. As per Gaydecki et al. (1992) using low frequencies in the area of 40 to $80 \mathrm{KHz}$ to assess the concrete. We used $54 \mathrm{KHz}$ frequency that in this research. This system could be used with different methods of the test: direct transmission, semi-direct transmission, indirect transmission. The direct transmission was considered as the most satisfactory method. Therefore direct transmission method was used in this research. Pulsar (transmitter) and receiver were put on the concrete sample surfaces as it is shown in "Figure 2". Before every speed measurement of ultrasonic waves, the sample was removed from the water bath and its surface was dried before putting the transducer and measurement. In order to ensure that there is a fixed and uninformed pressure between transducer and concrete sample, the transducers were pressed by hand to be put under the fixed pressure of 10 Newton. Ultrasound gel also was used as interface material (Couplant) between the transducer and Concrete surface. Then the samples were put under the test of pushing strength. It should be noted that the speed of waves' transmission for every sample is considered the average speed in two directions perpendicular to each other. Related strength is also similar to average strength.

Earlier the assessing of concrete by using ultrasonic method was mainly dependent on several factors according to the nature of the test. One of the most important of such factors is the influence of moisture. In order to reach the aim of the research, the control concrete samples are in three groups (3 Immersion time and different moisture content). Every group included 3 samples thus there were total 9 samples which were as follows: $2 \%$ fibrous concrete samples, $4 \%$ fibrous concrete samples, and concrete samples containing $7 \%$ micro silica by weight of cement, concrete samples containing $2 \%$ fiber and $7 \%$ micro silica by weight of cement, concrete samples containing $4 \%$ f iber and $7 \%$ micro silica by weight of cement also each one is made in three groups and each group including 3 sample. These samples were with a ratio of $\mathrm{W} / \mathrm{C}=0.61$ which were 54 samples in total with the same material and the water ratio was made to constant cement in the laboratory. After $24 \mathrm{hrs}$. the templates were opened. The samples were cured under the standard situation $20^{\circ} \mathrm{C} \pm 2^{\circ} \mathrm{C}, \mathrm{RH}>95 \%$ in the lab for the 28 day time out. After this period the samples were put in the dryer box (keeping the temperature in $45^{\circ} \mathrm{C}$ in order to prevent the cement damage in the high temperature) till the mass was not changed so that the sample could be considered completely dry. The mass was considered mo, and then the samples are put in the plastic tank which is full of water. In the first stage the mass of samples was recorded at every 20 minutes and after that, the distance between recordings increased to 1, 2, and $4 \mathrm{hrs}$. In this research immersion time was divided into three different hours of probably 1 hour, 2 hr., and $22 \mathrm{hr}$. which after specified immersion time the samples were taken out of the tank (in order to keep the moisture sample and to ensure that there was no water drop on the surface of samples, the sample were put on the iron for 5 minutes for external water discharge, and the surface were cleaned with a moist cloth after getting out of the tank) and their weight was measured that the mass was 
TECHNOSCIENCE ARTICLE

considered $m_{i}$ and the moisture of $\mathrm{M}$ sample can be calculated by the Eq. 1:

$$
\mathrm{M}=m_{1}-m_{o} / m_{\circ}
$$

where $m_{0}$ was the completely dry sample mass and $m_{\mathrm{i}}$ was the sample mass in an immersion specified period of time, it specifies the mass was measured under different conditions of moisture and after calculating the moisture content of samples of every group, the samples were put under the ultrasonic test and compressive strength.

\section{Results:}

The results of the time and speed of ultrasonic wave transmission determination by considering the moisture content, fibre content and, micro silica content. The results of control samples are mentioned in the "Table 4" for some samples separately. "Table 4 " shows the effect of different moisture contents on the speed of ultrasonic waves. The dominant trend in the above table reflects the fact that with the increase of time of immersion in water and consequently the increase of moisture content samples, the speed of ultrasonic waves is raised. It seems the direct relationship between speed and moisture content. It is because of capillary pore volume and holes and micro cracks concrete samples reduced with increased immersion time and moisture content by water molecules and capillary pore volume, and concrete samples are converted to more homogeneous body and as a result false strength of concrete is reduced against the directed waves.

The results for tests to determining the compressive strength including moisture content, fibre content, Micro silica, and results of the control samples, for concrete samples in 28 days are listed separately in "Table- 5 ".

The dominant trend in "Table- 5 " reflects the fact that with increased time of immersion of samples in water and consequently the increase of moisture content, the compressive strength of concrete samples is reduced.

Table 1: Physical characteristics of stony materials in concrete samples

\begin{tabular}{llll}
\hline $\begin{array}{l}\text { Values } \\
\text { Coarse-grained }\end{array}$ & $\begin{array}{l}\text { Physical characteristics } \\
\text { Calues }\end{array}$ & \multicolumn{2}{c}{$\begin{array}{l}\text { Physical characteristics } \\
\text { Fine-grained }\end{array}$} \\
\hline 2.57 & Special weight & 2.51 & Special weight \\
90 & Water absorption (\%) & 0.03 & Water absorption (\%) \\
19 & Breakage percent (\%) & 3 & Fitness module \\
\hline
\end{tabular}

Table 2: Physical \& mechanical properties of Forta polymer fibers

\begin{tabular}{ll}
\hline Confirmation & - ASTM C-1116 \\
Raw material & - Net copolymer Or polypropylene \\
Appearance & - Convolutedand single-strand fibers \\
color & - Gray \\
Strength in acidicand & \\
alkaline environments & - Excellent \\
Special Weight & -0.91 \\
length & $-54 \mathrm{Mm}$ \\
Tensile strength & $-570-660 \mathrm{Mpa}$
\end{tabular}

Table 3: Summary of the results of themixed design calculations forconcrete samples

\begin{tabular}{|c|c|c|}
\hline \multicolumn{2}{|c|}{ Concrete samples type } & \multirow[t]{2}{*}{ Unit } \\
\hline $\begin{array}{l}\text { Micro Silica \& } \\
\text { Micro Silica- } \\
\text { Fibrous }\end{array}$ & $\begin{array}{l}\text { Typical \& Fibrous } \\
\text { concrete }\end{array}$ & \\
\hline 205 & 205 & Water $\left(\mathrm{Kg} / \mathrm{m}_{3}\right)$ \\
\hline 312.55 & 336.07 & Cement $\left(\mathrm{Kg} / \mathrm{m}_{3}\right)$ \\
\hline 1020 & 1020 & Coarse-grained $\left(\mathrm{Kg} / \mathrm{m}_{3}\right)$ \\
\hline 783.93 & 783.93 & Fine-grained $\left(\mathrm{Kg} / \mathrm{m}_{3}\right)$ \\
\hline 2 & 2 & $\operatorname{Air}(\%)$ \\
\hline 1820 & 1820 & Fiber $0.2 \%\left(\mathrm{gr} / \mathrm{m}_{3}\right)$ \\
\hline 3640 & 3640 & Fiber $0.4 \%\left(\mathrm{gr} / \mathrm{m}_{3}\right)$ \\
\hline $23 \cdot 5^{2}$ & - & MicroSilica (Kg/m3) \\
\hline
\end{tabular}

Table 4: Results of time and speed of Ultrasonic waves in all of cube samples in Ultrasonic test

\begin{tabular}{|c|c|c|c|c|c|c|}
\hline \multirow[t]{2}{*}{$\mathrm{a}$} & \multicolumn{3}{|c|}{ Sample property } & \multirow[t]{2}{*}{ b } & \multirow[t]{2}{*}{ c } & \multirow[t]{2}{*}{ d } \\
\hline & * & ** & $\mathrm{w} / \mathrm{c}$ & & & \\
\hline \multirow{4}{*}{1} & & & & oh & 37.85 & 3963.01 \\
\hline & & & & $2 \mathrm{~h}$ & $37 \cdot 35$ & 4016.06 \\
\hline & & & & $14 \mathrm{~h}$ & 36.1 & 4155.12 \\
\hline & & & & $22 \mathrm{~h}$ & $35 \cdot 5$ & $4225 \cdot 35$ \\
\hline \multirow[t]{4}{*}{2} & & & & oh & 38.2 & 3926.7 \\
\hline & & & 0.61 & $2 \mathrm{~h}$ & 36.6 & 4098.68 \\
\hline & & & & $14 \mathrm{~h}$ & $35 \cdot 7$ & 4201.68 \\
\hline & & & & $22 \mathrm{~h}$ & 35.6 & 4213.48 \\
\hline \multirow[t]{4}{*}{7} & & & & oh & 38.7 & $3875 \cdot 96$ \\
\hline & 0.2 & - & 0.61 & $2 \mathrm{~h}$ & 38.6 & 3886.01 \\
\hline & & & & $14 \mathrm{~h}$ & 36.55 & 4103.96 \\
\hline & & & & $22 \mathrm{~h}$ & 36.5 & $4109 \cdot 58$ \\
\hline \multirow[t]{4}{*}{8} & & & & oh & 37.1 & 4043.12 \\
\hline & 0.2 & - & 0.61 & $2 \mathrm{~h}$ & 37 & 4054.05 \\
\hline & & & & $14 \mathrm{~h}$ & 35.6 & 4213.48 \\
\hline & & & & $22 \mathrm{~h}$ & $35 \cdot 45$ & 4231.31 \\
\hline \multirow[t]{4}{*}{14} & & & & oh & $39 \cdot 5$ & 3797.46 \\
\hline & & & & $2 \mathrm{~h}$ & 38.1 & 3937.007 \\
\hline & & & & $14 \mathrm{~h}$ & $37 \cdot 55$ & 3994.67 \\
\hline & & & & $22 \mathrm{~h}$ & 37.1 & 4043.12 \\
\hline \multirow[t]{4}{*}{15} & & & & oh & 38.45 & 3901.17 \\
\hline & 0.4 & - & 0.61 & $2 \mathrm{~h}$ & 37.95 & 3952.56 \\
\hline & & & & $14 \mathrm{~h}$ & 36.6 & 4098.36 \\
\hline & & & & $22 \mathrm{~h}$ & 36.45 & 4115.22 \\
\hline \multirow[t]{4}{*}{19} & & & & oh & 36.05 & 4160.88 \\
\hline & & & & $2 \mathrm{~h}$ & 35.6 & 4213.48 \\
\hline & & & & $14 \mathrm{~h}$ & 34.85 & 4304.16 \\
\hline & & & & $22 \mathrm{~h}$ & 34.6 & 4335.26 \\
\hline \multirow[t]{4}{*}{20} & & & & oh & 36.95 & 4059.53 \\
\hline & - & 7 & 0.61 & $2 \mathrm{~h}$ & 36.6 & 4098.36 \\
\hline & & & & $14 \mathrm{~h}$ & 34.85 & 4304.16 \\
\hline & & & & $22 \mathrm{~h}$ & $34 \cdot 55$ & 4341.53 \\
\hline \multirow[t]{4}{*}{28} & & & & oh & 38.3 & 3916.44 \\
\hline & & & & $2 \mathrm{~h}$ & 36.3 & 4132.23 \\
\hline & & & & $14 \mathrm{~h}$ & $35 \cdot 7$ & 4201.68 \\
\hline & & & & $22 \mathrm{~h}$ & 35.45 & 4231.31 \\
\hline
\end{tabular}




\begin{tabular}{lllllll}
29 & 0.2 & 7 & 0.61 & oh & 37.1 & 4043.12 \\
& & & & $2 \mathrm{~h}$ & 36.5 & 4109.58 \\
& & & & $14 \mathrm{~h}$ & 35.5 & 4225.35 \\
& & & $22 \mathrm{~h}$ & 35.4 & 4237.28 \\
\hline 32 & & & & oh & 36.2 & 4143.64 \\
& 0.4 & 7 & 0.61 & $2 \mathrm{~h}$ & 36 & 4166.66 \\
& & & $14 \mathrm{~h}$ & 34.75 & 4316.54 \\
& & & & $22 \mathrm{~h}$ & 34.6 & 4335.26 \\
\hline
\end{tabular}

a- Number of samples, b- Time immersion in water, c- The mean of transit time of ultrasonic waves $(\mu \mathrm{s}), \mathrm{d}$ - The mean of ultrasonic wavesspeed, *-The percentage of fiber, ${ }^{* *}$ - The percentage of MicroSilica.

\begin{tabular}{|c|c|c|c|c|c|}
\hline \multirow[t]{2}{*}{ a } & \multicolumn{3}{|c|}{ Sample property } & \multirow[t]{2}{*}{$\mathrm{b}$} & \multirow[t]{2}{*}{ c } \\
\hline & * & $* *$ & $\mathrm{w} / \mathrm{c}$ & & \\
\hline 1 & \multirow{3}{*}{-} & \multirow{3}{*}{-} & \multirow{3}{*}{0.61} & oh & $15 \cdot 35$ \\
\hline 2 & & & & $2 \mathrm{~h}$ & 13.78 \\
\hline 3 & & & & $22 \mathrm{~h}$ & 12.2 \\
\hline 7 & \multirow{3}{*}{0.2} & \multirow{3}{*}{-} & \multirow{3}{*}{0.61} & oh & 16.75 \\
\hline 8 & & & & $2 \mathrm{~h}$ & $15 \cdot 7$ \\
\hline 9 & & & & $22 \mathrm{~h}$ & 14.31 \\
\hline 14 & \multirow{3}{*}{0.4} & \multirow{3}{*}{-} & \multirow{3}{*}{0.61} & oh & 15 \\
\hline 15 & & & & $2 \mathrm{~h}$ & 13.26 \\
\hline 16 & & & & $22 \mathrm{~h}$ & $9 \cdot 77$ \\
\hline 19 & \multirow{3}{*}{0.4} & \multirow{3}{*}{7} & \multirow{3}{*}{0.61} & oh & 22.68 \\
\hline 20 & & & & $2 \mathrm{~h}$ & $19 \cdot 54$ \\
\hline 21 & & & & $22 \mathrm{~h}$ & 19.19 \\
\hline 28 & \multirow{3}{*}{0.2} & \multirow{3}{*}{7} & \multirow{3}{*}{0.61} & oh & $23 \cdot 37$ \\
\hline 29 & & & & $2 \mathrm{~h}$ & 21.28 \\
\hline 30 & & & & $22 \mathrm{~h}$ & 20.24 \\
\hline 32 & \multirow{3}{*}{0.4} & \multirow{3}{*}{7} & \multirow{3}{*}{0.61} & oh & 18.84 \\
\hline 35 & & & & $2 \mathrm{~h}$ & 17.1 \\
\hline 36 & & & & $22 \mathrm{~h}$ & 16.75 \\
\hline
\end{tabular}

a- Number of samples, b- Time immersion in water, c- Mean compressive strength (Mpa), d- The mean of ultrasonic wavesspeed, *-The percentage of fiber, ${ }^{* *}$ - The percentage of MicroSilica.

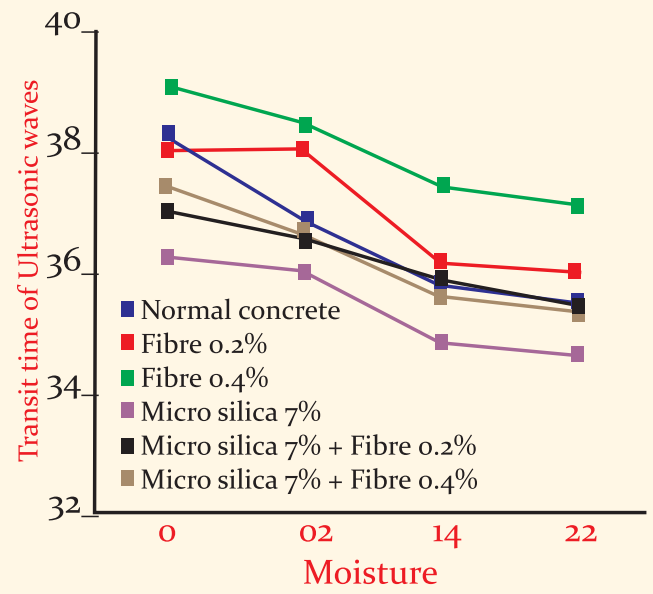

Figure 1. The effect of moisture content on the transit time of ultrasonic waves for all concrete samples with $\mathrm{W} / \mathrm{C}-0.61$

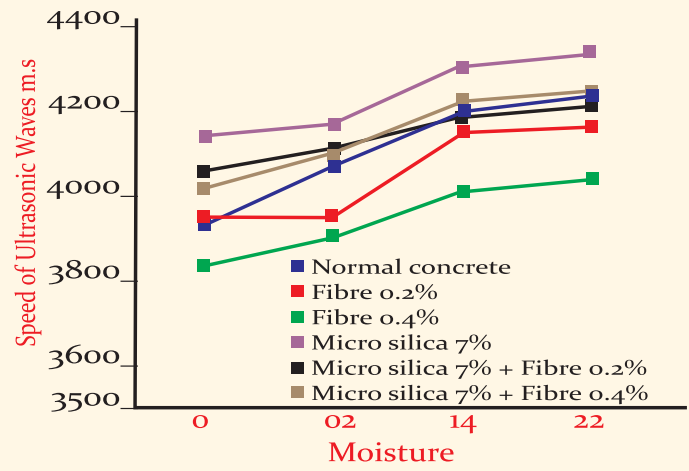

Figure 2: The effect of moisture content on the speed of ultrasonic waves for all concrete samples with $\mathrm{W} / \mathrm{C}-0.61$

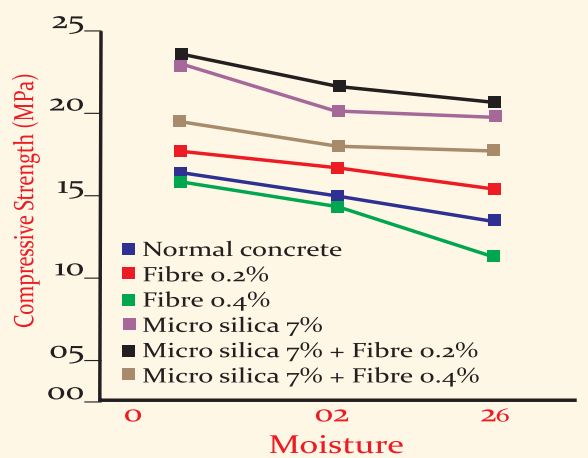

Figure 3: The effect of moisture content on the compressive strength for all concrete samples with W/C- - o.61

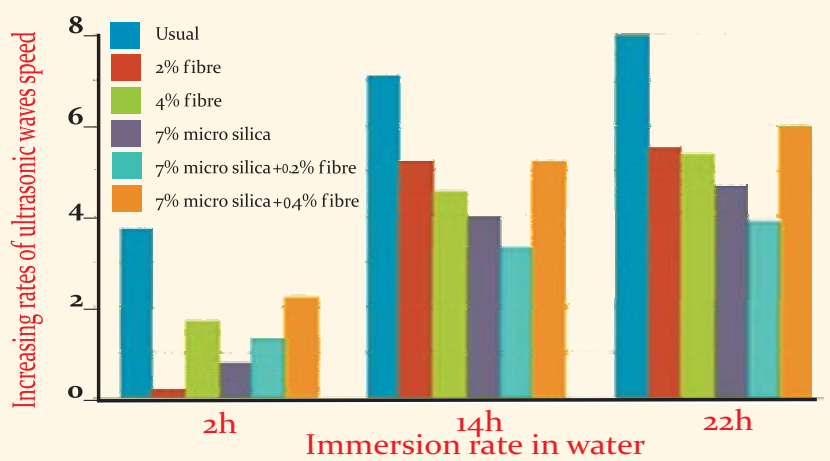

Figure-6: Increasing rate of ultrasonic weaves speeds used in the every moisture content.(Immersion rate in water per hour)

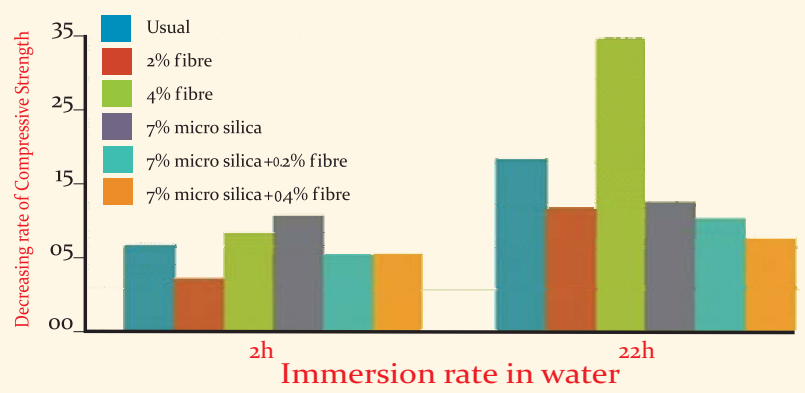

Figure 7. Decreasing rate of compressive strength of concrete samples used in the every moisture content (Immersion 


\section{Discussion:}

Again, in order to more analogy and more accurate conclusion, all of these variables are presented as to be consolidated in the following charts.

According to "Fig.-3" and "Fig.-4", it is clear that fibrous concrete samples $0.2 \%$ only in moisture o causes increased the speed of ultrasonic waves at a rate of $0.5 \%$ in comparison with normal concrete. Whereas in all the other samples with various moisture contents reduce the speed of ultrasonic waves in comparison with the control one. But fibrous concrete samples $0.4 \%$ in all of the moisture contents decreased the speed of waves in comparison with the control concrete samples. As well as, according to "Fig.- 4" micro silica concrete samples cause increased 5\%, and fibrous _micro silica concrete samples $0.2 \%$ cause raised $3 \%$ and fibrous micro silica concrete samples $0.4 \%$ cause increased $2.16 \%$ in the speed of waves in moisture o in comparison with normal concrete samples. Also, in immersion time 2, 14 and 22 hours in water the micro silica concrete samples respectively, cause increased $6.24 \%, 9.6 \%$, and $10.3 \%$ and micro silica-fibrous concrete $2 \%$ respectively, cause increased $4.5 \%, 7.5 \%, 8.24$ $\%$ in the speed of waves in comparison with normal concrete. As you see in "Fig.-4" with increased immersion time in the water and in moisture content, the speed of Ultrasonic waves in all of the samples raises.

According to the "Fig. -5 ", it is obvious that $0.2 \%$ fibrous concrete samples have made an increased compressive strength in all moisture content ratios to usual concrete samples but the $0.4 \%$ fibrous concrete samples have made a reduced compressive strength in comparison to usual concrete samples. According to the "Figure 5 " it is obvious that with micro silica, there is generally an increased strength ratio to control that concrete samples containing micro silica make it increases to $47.7 \%$, o.2\% micro silica fibrous concrete samples make it increases to $52.25 \%$, and $0.4 \%$ fibrous- micro silica concrete samples make it increases to 22.74 in compressive strength in zero moisture ratio to usual concrete samples. In the 2 and 22 hours immersion time in the water the micro silica concrete samples make it increases to $27.3 \%$ and $20.01 \%$ respectively and 0.2 fibrous-micro silica concrete samples make it increases to $38.64 \%$ and $31.86 \%$ respectively and $0.4 \%$ fibrous-micro silica concrete samples make it increases to $11.4 \%$ and $9.13 \%$ in compressive strength ratio to control concrete samples respectively.

As it is shown in "Fig.-3" to "Fig.-5" by increasing the immersion time of concrete samples in the water and increasing the moisture content, the time for ultrasonic wave transmission is decreased that following it the speed of waves is increased, but the increasing of moisture content, has reduced the compressive strength of samples.

Increasing rate of ultrasonic waves speed and decreasing rate of compressive strength of concrete samples is offered used in the every moisture content (immersion rate in water/ hour) in the "Fig.-6" \& "Fig.- 7".

As it is obvious in the Fig.- 6 the most increasing rate in ultrasonic waves speed for concrete samples ratio to dry status is for usual concrete samples by putting concrete samples in water and increasing moisture content where its rate was $7.99 \%$ ratio to dry status. It is also obvious in "Fig.-7" that by putting concrete samples in water and increasing moisture content, there was the greatest reduction in compressive strength ratio to dry status for samples $0.4 \%$ fibrous concrete that was made by increasing moisture content that its rate was $34.87 \%$ and the lowest reduction in compressive strength ratio to dry status was for fibrous-micro silica concrete samples that this reduction is $11.1 \%$.

\section{Conclusion:}

1. 1.In dry concrete samples the more the speed of waves, the more compressive strength. Perhaps the waves' speed and compressive strength have a direct relation together (British Standard, 1986).

2. By increasing immersion time in the water that is to increase the moisture content of samples, the speed of ultrasonic waves also increase.

3. By increasing the immersion time of samples in water that is to increase the moisture content of samples, the compressive strength of concrete samples decrease.

4. By putting concrete samples in water and increasing moisture content, waves' speed and compressive strength have show inverse relation (Trtnik \& Gams, 2014).

5. $0.2 \%$ fibrous concrete samples cause to increase the compressive strength in all moisture content ratios to usual concrete samples, but $0.4 \%$ fibrous concrete samples cause to decrease compressive strength ratio to usual concrete samples.

6. $0.2 \%$ fibrous concrete samples in the zero moisture cause to increase the speed of ultrasonic waves to the rate of $0.5 \%$ ratio to usual concrete samples, by putting concrete samples in water and increasing moisture content, $0.2 \%$ fibrous concrete samples decrease the speed of ultrasonic weaves ratio to usual concrete samples (Hadianfard \& Jafari, 2012).

7. $0.4 \%$ fibrous concrete samples in all moisture content cause to decrease the speed of waves than usual concrete samples (Madandoust et al., 2010).

8. Micro silica concrete samples cause to increase the speed of ultrasonic waves in all moisture content ratios to usual concrete samples.

9. Micro silica concrete samples cause to increase the compressive strength in all moisture content ratios to usual concrete samples.

10.By putting concrete samples in water and increasing moisture content, it shows the most increasing rate in ultrasonic waves' speed for concrete samples ratio to dry 
status and usual concrete samples (Voigt et al., 2005).

11. By putting concrete samples in water and increasing moisture content, the greatest reduction of compressive strength; ratio to dry status for $0.4 \%$ fibrous concrete samples and the least reduction in compressive strength ratio to dry status for fibrousmicrosilica..

\section{Acknowledgements:}

We aknowledge all the persons involved in this study reight from the concerned in charge for providing permission to the person help in conducting the study.

\section{References:}

Abo-Qudais, S. A. (2005): Effect of concrete mixing parameters on propagation of ultrasonic waves. Constr. Build. Mater., 19(4): 257-263.

British Standard (1986): Testing concrete: Part 203. Recommendations for measurement of velocity of ultrasonic pulses in concrete. BS 1881 : Part 203.

Bungey, J.H., Millard, S.G., \& Grantham, S.G (2006): Testing of concrete in structures. (4th Ed.).Pub.-Taylor \& Francis, London \& New York.

Demirboða, R., Türkmen, Ý., \& Karakoc, M.B. (2004): Relationship between ultrasonic velocity and compressive strength for high-volume mineral-admixtured concrete. Cement Concrete Res., 34(12):2329-2336.

Facaoaru, I. (1970): Non-Destructive Testing of Concrete in Romania, Symposium on NDT of Concrete and Timber," Institute of Civil Engineers, London, pp. 39-49.
Gaydecki, P.A., Burdekin, F.M., Damaj, W. \& John, D.G. (1992): The propagation and attenuation of medium-frequency ultrasonic waves in concrete: a signal analytical approach. Meas. Sci. Technol., 3(1): 126.

Hadianfard, M.A. \& Jafari, S. (2012): Checking the Compressive Strength of Concrete by Ultrasonic Test in a Fitting Exponential function Method, The second National Conference on Structural Geotechnical Earthquake, Mazandaran, Iran.

Lin, Y., Lai, C.P., \& Yen, T. (2003): Prediction of ultrasonic pulse velocity (UPV) in concrete. ACIMater. J., 100(1):21-28..

Madandoust, R., Shahabi, S.F. \& Ghavidel, R. (2010): Checking the Effect of Different Ratios of Concrete Mix Design on the speed of Ultrasonic Waves and Checking Compressive Strength by Using the Multivariate Regression Analysis. Fifth National Congress on Civil Engineering, Ferdowsi University of Mashhad, Iran

Malhotra, V.M. (1976). Testing hardened concrete: nondestructive methods (No. 9). Pub.: Iowa State University Press.

Trtnik, G. \& Gams, M. (2014): Recent advances of ultrasonic testing of cement based materials at early ages. Ultrasonics, 54(1): 66-75.

Voigt, Th., Grosse, Ch.U., Sun, Z., Shah, S.P. \& Reinhardt, H-W. (2005): Comparison of ultrasonic wave transmission and reflection measurements with $\mathrm{P}$-and S-waves on early age mortar and concrete. Mater. Struct., 38(8):729-738. 